\title{
Salivary flow, amylase, and total protein in hospitalized patients with HIV infection / AIDS complications
}

Núbia Carina de Oliveira ${ }^{1}$, Thayse Caroline de Oliveira ${ }^{1}$, Vanessa Cavassin Klamas ${ }^{1}$, Mateus Anhaia Ventura ${ }^{1}$, Adryano Arana Kamei ${ }^{1}$, Jhonatan Yukio Naka ${ }^{1}$, João Armando Brancher ${ }^{2}$, Antonio Adilson Soares de Lima ${ }^{1}$

1. Department of Stomatology, Universidade Federal do Paraná - UFPR, Curitiba/PR, Brazil.

2. School of Life's Sciences, Pontifícia Universidade Católica do Paraná - UFPR, Curitiba/PR, Brazil.

\begin{abstract}
Background: Saliva is a complex secretion produced daily by the salivary glands. Saliva consists mainly of water, enzymes, ions and amino acids and performs several important functions in oral health.

Objective: The aim of this study was to investigate the flow rate and concentrations of amylase and total proteins in the saliva of hospitalized patients due to AIDS complications.

Methods: Ninety-three men and women (20-64 years of age) were divided into two groups (46 HIV-infected patients and 47 controls) and had salivary flow rate and levels of amylase enzyme and total proteins evaluated.

Results: The mean salivary flow rate was lower in individuals with HIV when compared to controls $(\mathrm{P}<0.05)$. No significant difference between amylase enzyme levels and total proteins were observed in the saliva of patients with HIV infection when compared to controls.

Conclusion: Individuals with HIV / AIDS infection (in hospital treatment) suffer no interference in levels of amylase and total salivary proteins, but they have significantly reduced salivary flow.

Keywords: Saliva; Salivation; Alpha-Amylases; Salivary Proteins and Peptides; Xerostomia.

DOI: https://doi.org/10.4314/ahs.v20i2.7

Cite as: Carina de Oliveira N, Caroline de Oliveira T, Klamas VC, Ventura MA, Kamei AA, Naka JY, Brancher JA, Soares de Lima AA. Salivary flow, amylase, and total protein in hospitalized patients with HIV infection / AIDS complications. Afri Health Sci. 2020; 20(2): 597-604. bttps://doi.org/10.4314/abs.v20i2.7
\end{abstract}

\section{Introduction}

Saliva has been defined as a mirror of the body because it can reflect the levels of body fluids, natural substances and a wide variety of molecules introduced for therapeutic, recreational and addictive purposes. Besides, this secretion may change due to several emotional, hormonal, immunological, neurological, nutritional and metabolic states. ${ }^{1}$ Saliva has been studied, especially about its production and constituents. ${ }^{2}$ However, its physiologi-

\section{Corresponding author:}

Antonio Adilson Soares de Lima,

Curso de Odontologia -

Departamento de Estomatologia da UFPR

Rua Prefeito Lothário Meissner 632,

Jardim Botânico

80170-210 Curitiba - PR Brazil

Telephone: + 554133604026

E-mail: aas.lima@ufpr.br / antollima@gmail.com cal importance has only been recognized more recently. In the last 50 years, the rhythm of research involving saliva has accelerated with the use of new techniques that allowed the recognition of the biochemical and physico-chemical properties of this secretion.

Saliva performs several functions, such as speech, mucosal lubrication, food digestion and maintenance of oral and general health. ${ }^{3}$ Also, saliva promotes a lubricating effect that maintains the integrity of the mucosa and surfaces of the upper and lower gastrointestinal tract. Besides, it contributes as physical-chemical defense, antimicrobial and in the repair of wounds. ${ }^{4-5} \mathrm{Re}-$ cently, interest in saliva has increased due to the identification of several components that may serve to detect different systemic diseases or evidence of exposure to harmful substances, as well as to provide biomarkers of a particular disease. ${ }^{6}$

Complications associated with AIDS are responsible for several opportunistic diseases and neoplasia. Pneumonia is a complication and has been identified as the 
major cause of morbidity and mortality in individuals living with HIV.? Oftentimes, these diseases associated with AIDS can lead to the need for hospitalization of the patient. With the advent of antiretroviral therapy, the average number of hospitalizations of AIDS patients decreased. However, when a patient is hospitalized due to the complications associated with AIDS, the average time of hospitalization is 11 days of treatment. ${ }^{8}$ During the hospital stay, the patient may undergo some medical procedures, use various drugs and undergo several laboratory tests. Furthermore, it is natural for the patient to become anxious and stressed in this period of hospitalization. In this way, the period of hospitalization can affect your general and oral health.

Several studies have been conducted with saliva since the recognition that HIV infection can alter the functioning of the salivary glands. ${ }^{9-11}$ In 1992, Schiødt et al. ${ }^{12}$ have carried out biochemical analysis of the saliva of patients with HIV infection. At that time, the researchers observed a significant reduction in salivary protein levels, with elevation in salivary $\operatorname{IgA}$, lysozyme, and albumin when compared to negative controls. However, there is still no consensus on the actual impact of HIV infection and/or its treatment on the functioning of glands and the quality of saliva. There are many studies about total saliva proteins, mainly to associate changes in specific proteins to the progression of various diseases and to identify proteins that are related to specific disease phenotypes. Amylase is a protein found in saliva and has been proposed as a sensitive biomarker for stress-related changes in the body that reflect the activity of the sympathetic nervous system. ${ }^{13-14}$ Currently, several surveys are bringing results that support the validity and reliability of this parameter. ${ }^{15}$ However, there are few studies on the impact of AIDS on the concentration of amylase and total proteins in saliva. Thus, the objective of this study is to investigate the flow and concentrations of amylase and total proteins in the saliva of hospitalized patients due to AIDS complications.

\section{Methods}

\section{Ethics}

This study was approved by the Committee of Ethics in Research of the Universidade Federal do Paraná (Number. 1.627.826).

\section{Sample}

The sample of this study consisted of 93 adult individuals of both genders with and without the diagnosis of HIV infection. The patients were divided into two groups: a) Case group - Composed of 46 patients with a confirmed diagnosis of HIV infection; and b) Control group - 47 healthy individuals without HIV infection. Initially, the following information was collected from the medical record: personal data (name, age, sex, occupation, race, marital status, education, naturalness, and origin), reason for hospitalization, comorbidities, time of treatment with antiretroviral therapy, medications in use (antiretroviral drugs and others) and their history of smoking, alcohol and illicit drug use. Individuals who had any oral or systemic conditions that did not allow the collection of saliva were excluded from the study.

\section{Saliva collection}

Samples of total saliva were collected at the same time of day (9:00 a.m. - 11:00 a.m.). The stimulated total saliva was collected using a mechanical stimulus (a piece of sterile latex). All participants were initially instructed to chew the piece of latex for 1 minute. During this time, they could swallow the saliva produced. Then, the researcher timed another 5 minutes. During this time, the patient continued to chew the piece of latex and spit out the saliva produced in a previously weighed plastic pot (universal collector).

\section{Salivary flow analysis}

Salivary flow analysis was performed using the gravimetric technique. ${ }^{16}$ Initially, the saliva samples were weighed using a precision balance (Bell Engenharia, Brazil). The weight of the collected saliva was divided by collection time ( 5 minutes) and the salivary flow was expressed in $\mathrm{mL} / \mathrm{min}$. Hyposalivation was considered when the salivary flow was $\leq 0.6 \mathrm{~mL} /$ minute.

\section{Chemical analysis of saliva}

Each sample of saliva was centrifuged $(3,500 \mathrm{rpm})$ for 10 minutes to separate contaminant particles from saliva, such as desquamated epithelial cells, bacteria, blood cells, and food debris. Then, biochemical analyzes were performed using the colorimetric method (spectrophotometry) of amylase and total proteins. Amylase was measured using the method for determination of Alpha-Amylase (Bioclin, Quibasa química básica Ltda., Belo Horizonte/MG Brasil). In this technique, $\alpha$-Amylase catalyzes the hydrolysis of $\alpha$ - (2-Chloro-4-Nitrophenyl) - $\beta$-1.4-Galactopyranosylmaltoside (Gal-G2$\alpha$-CNP). It is present on the buffered substrate used, releasing 2-Chloro-4-Nitrophenol (CNP) and 1,4 Galactopyranosylmaltoside (Gal-G2). The catalytic concentration is determined from the rate of formation of 2-Chloro-4-nitrophenol. One milliliter of the reagent 
(buffered substrate) was added to $20 \mu \mathrm{L}$ of saliva in a test tube and homogenized manually. Then, the tube containing the mixture was taken to the spectrophotometer (BIO-200, Bioplus, Vila Nova, Barueri-SP / Brazil). An initial analysis of the sample was made and simultaneously the time of three minutes was counted with the help of a timer (SW2018, Chronobio, China). During this time, new readings were performed after 1 , 2 and 3 minutes. In this way, the concentrations of the amylase enzyme in T0, T1, T2, and T3 were obtained. The results were placed in the following formula and expressed in $\mathrm{U} / \mathrm{L}$ :

Amylases activity $=($ Tzero $+\mathrm{T} 1+\mathrm{T} 2+\mathrm{T} 3) / 4 \times 3954$

The Labtest Total Proteins system (Labtest Diagnóstica S.A., Lagora Santa /MG Brasil) was used for the analysis of total proteins. It is a method that has high sensitivity associated with the specificity of the biuret reaction and is one of the simplest and most accurate reactions for the determination of proteins in biological liquids. The system contains a Biuret Reagent and a Standard (bovine albumin $4 \mathrm{~g} / \mathrm{dL}$ and sodium azide $14.6 \mathrm{mmol} / \mathrm{L})$.

For the analysis, $50 \mu \mathrm{L}$ of saliva was mixed with $1 \mathrm{~mL}$ of biuret reagent. This mixture was then incubated at $37^{\circ} \mathrm{C}$ for 10 minutes before being read on the spectrometer. The reading value was transferred to the following formula and the total protein concentration in saliva expressed in $\mathrm{g} / \mathrm{dL}$ :
[Whole proteins $]=($ Test Absorbance $) /($ Standard Absorbance) $x 4 \mathrm{~g} / \mathrm{dL}$

\section{Statistical analysis}

The data collected were tabulated in an Excel for Windows software spreadsheet and analyzed using the SPSS program - Statistical Package for the Social Sciences (IBM Corp. Released in 2010. IBM SPSS Statistics for Windows, version 19.0 Armonk, NY: IBM Corporation, USA. Initially, the data were assessed for normality using the Levene Equality Test of Variances. Subsequently, the groups were compared using Student's t-test, ANOVA, Chi-square test, Mann-Whitney U test, and Fisher's exact test. The level of significance was $5 \%$. Data on the oral condition were tabulated in Excel for Windows software (Microsoft Corporation, Brazil) and statistically described through percentages and averages.

\section{Results}

Ninety-three samples of total stimulated saliva were used in this experiment (46 individuals with HIV / AIDS infection and 47 controls). Table 1 shows the sociodemographic characteristics of patients regarding age, gender, skin color, marital status, and origin. Most of the HIV-infected patients were white males $(60 \%)$, aged 20 to 64 years (Mean $+\mathrm{SD}=40.2+11.6$ ), single and living from the city of Curitiba. Patients in the control group had similar characteristics.

Table 1 - Socio-demographic characteristics of patients with HIV infection and controls.

\begin{tabular}{|c|c|c|c|c|c|}
\hline \multirow[t]{2}{*}{ Variables } & \multicolumn{2}{|c|}{ Case group } & \multicolumn{2}{|c|}{ Control group } & \multirow[b]{2}{*}{ Pvalue } \\
\hline & $\mathbf{N}$ & $\%$ & $\mathbf{n}$ & $\%$ & \\
\hline \multicolumn{6}{|l|}{ Age } \\
\hline $18-28$ old & 5 & 11 & 9 & 19 & \\
\hline $29-38$ old & 10 & 22 & 12 & 25 & \\
\hline $39-48$ old & 21 & 46 & 16 & 34 & $0.912 *$ \\
\hline $49-58$ old & 8 & 17 & 8 & 17 & \\
\hline $59-78$ old & 2 & 4 & 2 & 4 & \\
\hline \multicolumn{6}{|l|}{ Gender } \\
\hline Male & 28 & 60 & 29 & 62 & 1.000 \\
\hline Female & 18 & 40 & 18 & 38 & \\
\hline \multicolumn{6}{|l|}{ Skin color } \\
\hline White & 22 & 49 & 41 & 87 & $0.003^{* *}$ \\
\hline Not White & 18 & 39 & 6 & 12 & \\
\hline Uninformed & 6 & 13 & 0 & 0 & \\
\hline \multicolumn{6}{|c|}{ Marital status } \\
\hline Single & 24 & 52 & 17 & 36 & \\
\hline Married & 15 & 32 & 28 & 60 & \\
\hline Divorced & 3 & 6 & 2 & 4 & 0.086 \\
\hline Widower & 2 & 4 & 0 & 0 & \\
\hline Uninformed & 2 & 4 & 0 & 0 & \\
\hline \multicolumn{6}{|l|}{ Origin } \\
\hline Curitiba city & 30 & 65 & 31 & 66 & $0.000 * *$ \\
\hline Others cities & 16 & 34 & 16 & 34 & \\
\hline
\end{tabular}


The majority of patients with HIV infection worked in general service, sales and store and market activities $(37 \%)$. However, $20 \%$ of these individuals were unemployed. For the control group, most of the participants worked professionally as service workers, retailers in stores and markets (43\%). Unlike the case group, only one participant in the control group was unemployed $(2 \%)$.

The mean, mode, maximum and minimum values for flow, amylase and whole proteins are shown in table
2. The mean salivary flow of subjects with HIV infection was significantly lower when compared to controls (Case group $=0.79 \mathrm{~mL} / \mathrm{min}+0.44 /$ Control group $=$ $1.03 \mathrm{~mL} / \mathrm{min}+0.67 ; \mathrm{p}=0.012)$. However, when the hyposalivation criterion was used, $22(43 \%)$ individuals with HIV infection had this condition. Hyposalivation was observed in $19(37 \%)$ individuals of the control group. No statistical difference was observed between the groups for the amylase concentration $(p=0.34)$ and total proteins $(p=0.07)$.

Table 2 - Salivary flow, amylases, and whole proteins by groups.

\begin{tabular}{|c|c|c|c|c|c|c|c|c|c|}
\hline \multirow[t]{2}{*}{ Variables } & \multicolumn{4}{|c|}{ Case group } & \multicolumn{4}{|c|}{ Control group } & \multirow[t]{2}{*}{ P value } \\
\hline & Mean \pm SD & Mode & Maximum & Minimum & $\begin{array}{c}\text { Mean } \pm S \\
\text { D }\end{array}$ & Mode & Maximum & Minimum & \\
\hline $\begin{array}{l}\text { Salivary flow } \\
(\mathrm{mL} / \mathrm{min})\end{array}$ & $0.79 \pm 0.44$ & NV & 1.97 & 0.14 & $\begin{array}{c}1.03 \pm 0.6 \\
7\end{array}$ & $\mathrm{NV}$ & 3.19 & 0.13 & $0.040^{*}$ \\
\hline $\begin{array}{l}\text { Amylases } \\
(\mathrm{U} / \mathrm{L})\end{array}$ & $507.6 \pm 245.1$ & 412.2 & $1,450.1$ & 288.64 & $\begin{array}{c}453.2 \pm 29 \\
9.4\end{array}$ & 438.9 & 2.287 .3 & 291.6 & 0.341 \\
\hline $\begin{array}{l}\text { Whole } \\
\text { proteins (g / dL) }\end{array}$ & $1.4 \pm 0.8$ & 0.97 & 6.45 & 0.79 & $1.1 \pm 0.3$ & 0.92 & 2.54 & 0.74 & 0.074 \\
\hline
\end{tabular}

The oral condition of the study participants is presented in table 3. In this study, the oral condition of the HIV-infected individuals was worse than the controls, since they had a higher percentage of periodontal disease, residual roots, of lost teeth, oral ulcer and oral candidosis. Besides, an odds ratio was calculated for each variable.

The use of drugs, addictions, and other comorbidities is shown in table 3. The results revealed that not all patients with HIV infection were being treated with antiretroviral drugs. Of the total sample, $76 \%$ were already using antiretroviral therapy and the most used drugs were: Atazanavir, Lamivudine, Tenofovir, and Ritonavir. During the anamnesis, it was recorded that $55 \%$ of the individuals in the case group and $10 \%$ of the controls were smokers. On the other hand, alcoholic individuals represented 16\% in both groups. 
Table 3 - Oral health, use of medication, smoking, and alcoholism in patients with HIV infection and controls.

\begin{tabular}{|c|c|c|c|c|c|c|}
\hline Variables & $\begin{array}{c}\text { Case } \\
\text { Group } \\
\text { N (\%) }\end{array}$ & $\begin{array}{c}\text { Control } \\
\text { Group } \\
\mathrm{N}(\%) \\
\end{array}$ & $\begin{array}{l}\text { Total } \\
(\%)\end{array}$ & $P$ value & $\begin{array}{l}\text { Odds } \\
\text { rate }\end{array}$ & CI $95 \%$ \\
\hline Oral Health & & & & & & \\
\hline Periodontal diseases & $23(69.7)$ & $10(30.3)$ & $33(100)$ & $0.003^{*}$ & 3.614 & $1.498-8.720$ \\
\hline Coated tongue & $32(64)$ & $18(36)$ & $50(100)$ & $0.003 *$ & 3.368 & $1.511-7.508$ \\
\hline Residual root & $16(100)$ & $0(0)$ & $16(100)$ & $0.000^{*}$ & 0.393 & $0.304-0.309$ \\
\hline Dry mucosa & $9(69.2)$ & $4(30.8)$ & $13(100)$ & $0.111^{*}$ & 2.679 & $0.770-9.323$ \\
\hline Lost teeth & $35(70)$ & $15(30)$ & $50(100)$ & $0.000 *$ & 5.688 & $2.457-13.165$ \\
\hline Atrophic glossitis & $8(100)$ & $0(0)$ & $8(100)$ & $0.002^{* *}$ & 0.443 & $0.355-0.554$ \\
\hline Oral ulcer & $7(100)$ & $0(0)$ & $7(0)$ & $0.005^{* *}$ & 0.449 & $0.361-0.559$ \\
\hline Melanic hyperpigmentation & $10(90.9)$ & $1(9.1)$ & $11(100)$ & $0.003^{*}$ & 12.927 & $1.590-105.105$ \\
\hline Hairy tongue & $1(100)$ & $0(100)$ & $1(100)$ & $0.486^{* *}$ & 0.481 & $0.394-0.587$ \\
\hline Herpes zoster & $1(100)$ & $0(100)$ & $1(100)$ & $0.486^{* *}$ & 0.481 & $0.394-0.587$ \\
\hline Oral candidose & $12(100)$ & $0(0)$ & $12(100)$ & $0.000^{*}$ & 0.419 & $0.330-0.533$ \\
\hline $\begin{array}{l}\text { HIV Infection } \\
\text { Positive } \\
\end{array}$ & $47(100)$ & $0(0)$ & $47(100)$ & - & - & - \\
\hline Use of medication & & & & & & \\
\hline Antirretroviral drugs & $34(66)$ & $0(0)$ & 34 & - & - & - \\
\hline Abacavir & $1(1.9)$ & $0(0)$ & 1 & - & - & - \\
\hline Atazanavir & $10(19.6)$ & $0(0)$ & 10 & - & - & - \\
\hline Didanosine & $1(1.9)$ & $0(0)$ & 1 & - & - & - \\
\hline Efavirenz & $13(25.4)$ & $0(0)$ & 13 & - & - & - \\
\hline Fosamprenavir & $1(1.9)$ & 0 & 1 & - & - & - \\
\hline Lamivudine & $23(45)$ & 0 & 23 & - & - & - \\
\hline Lopinavir & $6(11.7)$ & $0(0)$ & 6 & - & - & - \\
\hline Norvir & $1(1.9)$ & $0(0)$ & - & - & - & - \\
\hline Ritonavir & $14(27.4)$ & $0(0)$ & - & - & - & - \\
\hline Tipranavir & $1(1.9)$ & $0(0)$ & - & - & - & - \\
\hline Tenofovir & $24(47)$ & $0(0)$ & - & - & - & - \\
\hline Zidovudine & $5(9.8)$ & $0(0)$ & - & - & - & - \\
\hline Addictions & & & & & & \\
\hline Smoking & $8(50)$ & $8(50)$ & $16(100)$ & - & - & - \\
\hline Alcoholism & $14(70)$ & $6(30)$ & $20(100)$ & - & - & - \\
\hline
\end{tabular}

\section{Discussion}

AIDS has been generally observed in the young male population with a low sociocultural level. Also, HIV has often been transmitted through heterosexual sexual contact. However, despite all the advances in prevention and treatment, it continues to be diagnosed in its later stages. ${ }^{17} \mathrm{HIV}$ destroys the defense cells (TCD4 + lymphocytes), which allows the development of opportunistic diseases and neoplasias. In addition to the immune system, HIV infection often compromises the functioning of other tissues and organs, such as the salivary glands. Some patients may develop diffuse infiltrative lymphocytosis syndrome and others only manifest hyposalivation. To date, there is still much discussion about the salivary changes of the quantitative and qualitative nature associated with HIV infection.
Salivary flow, buffer capacity, $\mathrm{pH}$, concentrations of inorganic and organic components can be altered in the function of several systemic factors. ${ }^{18}$ This study analyzed samples of total saliva collected between June and November 2016 from patients treated at Oswaldo Cruz Hospital (Curitiba - Brazil), which is a reference site for the treatment of AIDS in the state of Paraná. The study revealed that individuals with HIV infection had reduced salivary flow when compared to healthy individuals. On the other hand, despite the low salivary flow, no significant changes were observed in the salivary levels of the amylase enzyme and the total proteins. Salivary flow is a very important parameter when one wants to investigate the susceptibility of an individual, mainly to caries disease. Its measurement (sialometry) is indicated 
in clinical practice in the following situations: 1) as part of the initial examination of a "new" patient who will undergo dental treatment, 2) during the evaluation of a certain prophylactic and therapeutic treatment of caries disease, and (3) as part of the arsenal of examinations to establish the diagnosis of a hyposalivation. ${ }^{19}$

Saliva is a fluid of organic and inorganic composition produced and excreted by the major and minor salivary glands. The composition of the saliva produced by any of the glands varies according to the velocity of the flow that also changes according to the type, intensity, and stimulus applied on the glands. ${ }^{20}$ Under physiological conditions, adults produce approximately 500 to $1,500 \mathrm{~mL}$ of saliva per day and between 0 and $6 \mathrm{~mL} /$ min. ${ }^{21}$ It plays an important role as a physical-chemical barrier, as well as in the immune defense of the surfaces of the buccal mucosa. ${ }^{22}$

In the present study, the salivary flow of individuals with HIV infection was considered low when compared to controls. These findings corroborate the results of Lin et al. ${ }^{8}$ and Liberali et al. ${ }^{11}$. These authors also observed a significant reduction in the salivary flow of individuals with HIV. It is important to mention that no patient with diffuse infiltrative lymphocytosis syndrome was included in this study. In addition to the changes caused by HIV in the glandular tissue, other factors may also have contributed to reduced salivary flow. One of these factors was smoking since $67 \%$ of the samples were smokers and $50 \%$ presented hyposalivation. These findings corroborate the results of the study developed by Dyasanoor and Saddu ${ }^{23}$. These authors observed that $43 \%$ of the smokers presented hyposalivation. Long-term smoking significantly reduces salivary flow and increases oral and dental disorders associated with dry mouth, especially cervical caries, gingivitis, dental mobility, calculus, and halitosis. ${ }^{24}$

Hypofunction of salivary glands (resulting in low salivary flow) has been frequently observed among HIV-infected patients. ${ }^{25-26}$ Alterations in salivary flow may be associated with the progression of the disease by HIV or the patients' immune status. ${ }^{26}$ Many drugs may also influence the production of saliva and result in low salivary flow. ${ }^{27}$ Antiretroviral therapy, especially protease inhibitors, may interfere with the functioning of the salivary glands and cause hyposalivation. According to Navazesh et al. ${ }^{28}$, highly active antiretroviral therapy based on protease inhibitors represents a significant risk factor for the development of reduced non-stimulated and stimulated salivary flow as well as increased salivary glands. In our study, $74 \%$ of the subjects in the case group were using antiretroviral therapy. Of this total, the following protease inhibitors were used: Ritona$\operatorname{vir}(30 \%)$, Atazanavir (22\%), Lopinavir (13\%), Fosamprenavir $(2 \%)$, and Tipranavir $(2 \%)$. The reduction of salivary flow has been reported in subjects undergoing long-term HAART. 9 Ongoing chronic inflammation may potentially affect the salivary glands despite the modifying and beneficial effects of HAART. ${ }^{29}$

In addition to antiretroviral drugs, some patients included in this study used other drugs capable of inducing hyposalivation, such as antidepressants and anxiolytics. The neuronal regulation of salivation is controlled by the autonomic sympathetic and parasympathetic nervous systems. Thus, all drugs that interfere in the central and peripheral nervous systems may influence the production of saliva. Some medications may interfere with nerve stimulation, while others may impair or alter the functions of glandular acini or ducts. These effects may be hypersalivation or hyposalivation, both being sources of discomfort. ${ }^{21}$

Whole salivary proteins represent a vital component of this secretion. According to Edgar $^{30}$, in each 100 $\mathrm{mL}$ of saliva, there are about 200 to $300 \mathrm{mg}$ of proteins. Salivary proteins mainly comprise those rich in proline, mucins, amylase, immunoglobulins, statins and antibacterial factors. These proteins are responsible for several functions in the oral environment. ${ }^{31}$ The results of the present study revealed that there was no significant change in total protein levels of salivary amylase in patients with HIV infection. Our findings differ from Schiødt et al. ${ }^{12}$. These authors observed a significant reduction in salivary protein levels, with elevation in salivary IgA, lysozyme, and albumin in the saliva of HIV patients. Surprisingly, despite the reduction in salivary flow, the production and secretion of saliva do not appear to change in patients with AIDS.

Salivary amylase is involved in the digestion of dietary starch and also in the process of defense of the oral environment by the inhibition of bacteria. 32 The release of salivary amylase is neurologically controlled by acinar cells that are innervated by the sympathetic and parasympathetic branches of the autonomic nervous system..$^{33}$ There are a wide variety of proteins that are unique to the salivary fluid. These proteins perform biological functions of particular importance for oral health. Many of these proteins contain high levels (35$40 \%$ ) of proline (called proline-rich proteins or PRPs). PRPs comprise almost $70 \%$ of the whole proteins pro- 
duced by the human parotid. ${ }^{34}$ The amylase comprises most of the whole proteins of the parotid saliva. The other proteins (such as lysozyme, lactoferrin, peroxidase and IgA secretors) are relatively minor components. Recently, these proteins have received more attention in attempts to connect saliva and oral health. ${ }^{35}$

Some authors believe that amylase is involved in the functioning of the immune system by the inhibition of bacteria. ${ }^{32}$ These protective effects of saliva are evidenced by the excessive microbial growth found in patients with salivary deficiencies. ${ }^{36}$ Salivary antimicrobial proteins are considered an important part of the nonimmune host defense system that acts to prevent colonization and infection of the mouth by microorganisms.

In addition to digestion and protection, salivary amylase is a highly stress-sensitive enzyme that can affect other vulnerable biological systems when the individual is stressed. ${ }^{37}$ Specifically, amylase is considered the main stress mediator for its precursor activity on adrenaline and noradrenaline neurotransmitters. ${ }^{38}$ The level of amylase was expected to be higher in the saliva of the case group because the saliva samples analyzed were from hospitalized patients whose stress level is generally higher compared to healthy individuals. However, the results showed that the levels of this salivary enzyme did not change.

When the salivary glands do not function properly, the patient may develop caries, enamel erosions, and other dental demineralization, oral candidosis, and xerostomia. ${ }^{39-40}$ Salivary antimicrobial proteins are considered an important part of the non-immune host defense system in preventing colonization and mouth infection by microorganisms. The results of this study demonstrate that hospitalized patients due to AIDS complications have a lower salivary flow but unaltered levels of total proteins and salivary amylase. As the amount of saliva available in the mouth of the AIDS patient is considered insufficient, this may contribute to poor oral health that will negatively reflect the quality of life of these individuals. Thus, dentists who treat patients with this disease need to be aware of this fact and establish preventive measures, especially against caries and oral opportunistic infections.

\section{Acknowledgment}

Hospital Oswaldo Cruz - SESA and Dr Alceu Fontana Pacheco Junior.

\section{References}

1. Mandel ID. 1993. Salivary diagnosis: promises, promises. Ann N Y Acad Sci, 694(1):1-10.

2. Garrett JR. 1975. Changing attitudes on salivary secretion-a short history on spit. Proc R Soc Med, 68(9): 553.

3. Bafghi AF, Tabrizi AG \& Bakhshayi P. 2015. The Effect of smoking on mineral and protein composition of saliva. Iran J Otorbinolaryngol, 27(81):301-5.

4. Dawes C, Pedersen AM, Villa A, Ekström J, Proctor GB, Vissink A, Aframian D, McGowan R, Aliko A, Narayana N, Sia YW, Joshi RK, Jensen SB, Kerr AR \& Wolff A. 2015. The functions of human saliva: A review sponsored by the World Workshop on Oral Medicine VI. Arch Oral Biol, 60(6):863-74.

5. Schipper RG, Silletti E \& Vingerhoeds MH. 2007. Saliva as research material: Biochemical, physicochemical and practical aspects. Arch Oral Biol, 52(12): 1114-1135. 6. Lin AL, Johnson DA, Sims CA, Stephan KT \& Yeh CK. 2006. Salivary gland function in HIV-infected patients treated with highly active antiretroviral therapy (HAART). Oral Surg Oral Med Oral Pathol Oral Radiol Endod, 102(3):318-24.

7. Figueiredo-Mello C, Naucler P, Negra M \& Levin AS. 2017. Prospective etiological investigation of community-acquired pulmonary infections in hospitalized people living with HIV. Medicine, 96 (4): e5778.

8. Coelho LE, Escada ROS, Barbosa HPP, Santos VGV \& Grinsztejn BGJ. 2016. O tratamento da coinfecção HIV-TB. BJID Educação Médica Continuada, 2 (5):134-48. 9. Nittayananta W, Chanowanna N, Jealae S, Nauntofte B \& Stoltze K. 2010. Hyposalivation, xerostomia and oral health status of HIV-infected subjects in Thailand before HAART era. J Oral Pathol Med, 39(1):28-34.

10. Busato IM, Thomaz M, Toda AI, Alanis DG, França BH, de Lima AA \& Azevedo-Alanis LR. 2013. Prevalence and impact of xerostomia on the quality of life of people living with HIV/AIDS from Brazil. Spec Care Dentist, 33(3):128-32.

11. Liberali SA, Coates EA, Freeman AD, Logan RM, Jamieson L \& Mejia G. 2013. Oral conditions and their social impact among HIV dental patients, 18 years on. Aust Dent J, 58(1):18-25.

12. Schiødt M, Dodd CL, Greenspan D, Daniels TE, Chernoff D, Hollander H, Wara D \& Greenspan JS. 1992. Natural history of HIV-associated salivary gland disease. Oral Surg Oral Med Oral Pathol, 74(3):326-31.

13. Nater UM \& Rohleder N. 2009. Salivary alpha-amylase as a non-invasive biomarker for the sympathetic nervous system: current state of research. Psychoneuroendocrinol, 34(4): 486-96. 
14. Vineetha R, Pai KM, Vengal M, Gopalakrishna K \& Narayanakurup D. 2014. Usefulness of salivary alpha amylase as a biomarker of chronic stress and stress related oral mucosal changes - a pilot study. J Clin Exp Dent, 6(2): e132-137.

15. Cozma S, Dima-Cozma LC, Ghiciuc CM, Pasquali V, Saponaro A \& Patacchioli FR. 2017. Salivary cortisol and a-amylase: subclinical indicators of stress as cardiometabolic risk. BrazJ Med Biol Res, 50(2): e5577.

16. Banderas-Tarabay JA, González-Begné M, Sánchez-Garduño M, Millán-Cortéz E, LópezRodríguez A \& Vilchis-Velázquez A. 1997. The flow and concentration of proteins in human whole saliva. Salud Publica Mex, 39(5):433-41.

17. Ertunc B, Kaya S \& Koksal I. 2016. Clinico-epidemiological analysis of HIV / AIDS patients. The Eurasian J Med, 48(3): 157-61.

18. Navazesh M. Methods for collecting saliva. 1993. Ann N Y Acad Sci. 694(1):72-7.

19. Tenovuo J, Lagerlöf F. Saliva. In Thylstrup A \& Fejerskov O. 1995. Cariologia Clínica. 2nd ed. São Paulo: Livraria Santos Editora, p. 17-43.

20. Jenkins, GN. 1978. Saliva. In: The physiologic and biochemistry of the mouth. 4ed. Oxford: Blackwell Scientific Publications, p. 284-359.

21. Aps JK, Martens LC. 2005. Review: The physiology of saliva and a transfer of drugs into saliva. Forensic $S_{c i}$ Inter, 150(2-3): 119-131.

22. Fábián TK, Hermann P, Beck A, Fejérdy P \& Fábián G. 2012. Salivary defense proteins: their network and role in innate and acquired oral immunity. Int J Mol Sci, 13(4): 4295-320.

23. Dyasanoor S \& Saddu S. 2014. Association of Xerostomia and Assessment of Salivary Flow Using Modified Schirmer Test among Smokers and Healthy Individuals: A Preliminutesary Study. J Clin Diagn Res, 8(1): 211-3.

24. Raad D, Gaddam S, Schunemann HJ, Irani J, Abou Jaoude P, Honeine R \& Akl EA. 2011. Effects of water-pipe smoking on lung function: a systematic review and meta-analysis. Chest, 139 (4): 764-74.

25. Mandel ID, Barr CE \& Turgeon L. 1992. Longitudinal study of parotid saliva in HIV-1 infection. J Oral Pathol Med, 21(5): 209-13.

26. Sweet SP, Rahman D \& Challacombe SJ. 1995. IgA subclasses in HIV-disease: dichotomy between raised levels in serum and decreased secretion rates in saliva. Immunology, 86(4): 556-9.

27. Atkinson JC, Schiødt M, Robataille S, Greenspan D, Greenspan JS \& Fox PC. 1993. Salivary autoantibodies in HIV associated salivary gland disease. I Oral Pathol Med, 22(5): 203-6.

28. Navazesh M, Mulligan R, Karim R, Mack WJ, Ram S, Seirawan H, Greenspan J, Greenspan D, Phelan J, \& Alves M. 2009. Oral Substudy of the Women's Interagency HIV Study Collaborative Study Group*. Effect of HAART on salivary gland function in the Women's Interagency HIV Study (WIHS). Oral Dis, 15(1):52-60.

29. Jeganathan S, Carey H \& Purnomo J. 2012. Impact of xerostomia on oral health and quality of life among adults infected with HIV-1. Special Care Dent, 32 (4):1305.

30. Edgar WM. 1992. Saliva, its secretion, composition, and functions. Brit Dent J, 172(8):305-312.

31. Panchbhai AS, Degwekar SS \& Bhowte RR. 2010. Estimation of salivary glucose, salivary amylase, salivary total protein and salivary flow rate in diabetics in India. J Oral Sci, 52(3): 359-68.

32. Scannapieco FA. 1994. Saliva-bacterium interactions in oral microbial ecology. Crit Rev Oral Biol Med, 5(3-4): 203-48.

33. Emmelin N. Nerve interactions in salivary glands. $J$ Dent Res. 1987; 66(2):509-17.

34. Kauffman DL \& Keller PJ. 1979. The basic proline-rich proteins in human parotid saliva from a single subject. Arch Oral Biol, 24(4): 249-56.

35. Dodds MWJ, Johnsonb DA \& Yehc C. 2005. Health benefits of saliva: a review. J Dentistry, 33(3): 223-33.

36. Alves, TP, Simões ACDC, Simões ACD, Soares RMA, Moreno DAS, Portela MB \& Castro GFBA. 2014. Salivary lactoferrin in HIV-infected children: Correlation with Candida albicans carriage, oral manifestations, HIV infection and its antifungal activity. Arch Oral Biol, 59(8): 775-82.

37. Booij SH, Bos EH, Bouwmans MEJ, Van Faassen M, Kema IP, Oldehinkel AJ \& de Jonge P. 2015. Cortisol and $\alpha$-amylase secretion patterns between and within depressed and non-depressed individuals. PLoS One, 10(7):e0131002.

38. Allen AP, Kennedy PJ, Cryan JF, Dinan TG \& Clarke G. 2014. Biological and psychological markers of stress in humans: focus on the Trier social stress test. Neurosci Biobehav Res, 38(2014):94-124.

39. Navazesh M, Christensen CM \& Brightman VJ. 1992. Clinical criteria for the diagnosis of salivary gland hypofunction. J Dent Res. 71(7):1363-69.

40. Pedersen AM, Reibel J, Nordgarden H, Bergem HO, Jensen JL\& Nauntofte B. 1999. Primary Sjogren's syndrome: salivary gland function and clinical oral findings. Oral Diseases, 5(2):128-38. 